\title{
Establishment of a novel human cell line retaining the characteristics of the original pancreatic adenocarcinoma, and evaluation of MEK as a therapeutic target
}

\author{
XIAOXIAO DU ${ }^{1}$, KUIFENG HE ${ }^{1}$, YINGYING HUANG ${ }^{1}$, ZHENZHEN XU $^{1}$, \\ MEI KONG ${ }^{2}$, JING ZHANG ${ }^{1}$, JIANG CAO $^{3}$ and LISONG TENG ${ }^{1}$ \\ Departments of ${ }^{1}$ Surgical Oncology and ${ }^{2}$ Pathology, The First Affiliated Hospital, School of Medicine, \\ Zhejiang University, Hangzhou, Zhejiang 310003; ${ }^{3}$ Clinical Research Center, The Second Affiliated Hospital, \\ School of Medicine, Zhejiang University, Hangzhou, Zhejiang 310009, P.R. China
}

Received August 29, 2019; Accepted December 13, 2019

DOI: 10.3892/ijo.2020.4965

\begin{abstract}
Pancreatic cancer is a lethal solid malignancy with limited therapeutic options. The development of novel therapeutic drugs requires adequate new cell line models. A new pancreatic cancer cell line, designated PDXPC1, was established from one pancreatic ductal adenocarcinoma (PDAC) patient-derived xenograft. The PDXPC1 cells were stably cultured for $>2$ years and had a stable short tandem repeat profile. The PDXPC1 cell line retained the key mutations of the primary tumor, along with the epithelial origin and other important protein expression. The PDXPC1 cells induced rapid in vivo tumor growth, both subcutaneously and orthotopically, in a mouse model with an elevated CA199 level. The PDXPC1 cells showed weak growth, invasion and migration potency compared to another pancreatic cancer cell line, but were relatively resistant to multiple anti-cancer drugs. Interestingly, the MEK inhibitor trametinib significantly inhibited the proliferation of PDXPC1 cells, and not that of Panc-1 cells, by inactivating MEK/ERK/MYC signaling and activating the apoptotic pathway via Bcl-2 degradation. In conclusion, the PDXPC1 cell line, capturing the major characteristics of the primary tumor, may be a suitable tool for studying the underlying mechanisms of chemo-resistance in PDAC and developing new targeted therapeutic options.
\end{abstract}

\section{Introduction}

Pancreatic cancer (PC) is a highly aggressive malignancy that is typically diagnosed at the advanced stage, when few

Correspondence to: Professor Lisong Teng, Department of Surgical Oncology, The First Affiliated Hospital, School of Medicine, Zhejiang University, Building 7, 79 Qinchun Road, Hangzhou, Zhejiang 310003, P.R. China

E-mail: 1steng@zju.edu.cn

Key words: pancreatic ductal adenocarcinoma, cell lines, MEK inhibitor therapeutic options are viable (1). Despite decades of research and clinical trials, the 5-year survival rate of PC is a poor 5\%, and the median survival duration is $<6$ months (2). Pancreatic ductal adenocarcinoma (PDAC) is the most common histological subtype of pancreatic neoplasms (3), and is predicted to become the second leading cause of cancer-related death in the United States by 2030 (4). The poor clinical outcome of PDAC is due to its invasive progression and distant metastasis, which is often non-resectable at the time of diagnosis (1).

Currently, gemcitabine-based chemotherapy is the standard treatment prescribed for patients with advanced PDAC. However, its efficacy is limited due to intrinsic or acquired drug resistance (5). Although the recently approved FOLFIRINOX regimen (comprising fluorouracil, leucovorin, irinotecan and oxaliplatin) elicited an improved response from patients and increased overall survival compared to gemcitabine monotherapy, it is recommended only for a small group of patients due to its side effects (6). Therefore, it is essential to elucidate the underlying molecular mechanisms of PDAC, in order to identify effective therapeutic targets. To that end, there is a need for physiologically relevant models to simulate PDAC.

Cancer cell lines remain the primary in vitro model for basic and translational cancer research. However, the currently available pancreatic cancer cell lines were established several decades ago, and may have been unintentionally cross-contaminated with other cells (7). In addition, these decades-old cell lines lack sufficient clinical information and reliable certification, which has hindered research progression (8).

Accordingly, there is an urgent need for the production of novel, well-established, fully characterized cancer cell lines for research use. However, establishing cancer cell lines directly from tumor samples is inefficient, while protocols for deriving cancer cell lines from xenografts with a high success rate have proved useful in other types of cancer research, including for colon cancer and liver cancer $(9,10)$.

The present study successfully established and fully characterized a pancreatic cancer cell line derived from a PDAC patient-derived xenograft (PDX). The genetic alterations and phenotypes of the derived cell line were consistent with those of the parent PDAC tumor. This well-established novel human 
pancreatic cancer cell line is preferable for translational and molecular studies, and can be a powerful tool to study the chemoresistance patterns of tumors, and a subset of PDAC patients may benefit from MEK inhibition treatment.

\section{Materials and methods}

Patient samples. The tissue sample was obtained from a patient with PC who had undergone surgery at the Department of Surgical Oncology, The First Affiliated Hospital of Zhejiang University School of Medicine in August 2012. The tumor sample was confirmed by at least two pathologists. The study was approved by the Ethical Review Committee of The First Affiliated Hospital of Zhejiang University School of Medicine, and written informed consent was obtained from the patient.

Establishment of the PDX-derived cell line. The patient-derived pancreatic cancer xenografts were established as previously described (11). Briefly, patient tumor pieces were subcutaneously implanted into five 4-6 week-old female BALB/c nude mice obtained from the Model Animal Research Center of Nanjing, and the tumors were measured every 5 days. The tumors were harvested for second and third transplantation when they grew to $1,242.9 \pm 307.4 \mathrm{~mm}^{3}$ (largest diameter: $17.0 \pm 2.2 \mathrm{~mm}$ ) and $1,196.6 \pm 136.4 \mathrm{~mm}^{3}$ (largest diameter: $17.3 \pm 1.4 \mathrm{~mm}$ ), respectively. The third generation PDXs were harvested when the volume reached $157.5 \pm 17.2 \mathrm{~mm}^{3}$, and were then used for establishing the cell line and other assays.

The cell line was established from the PDX using a method reported in a previous study (12). The xenografts were enzymatically digested, and then minced into small pieces $\left(<1 \mathrm{~mm}^{3}\right)$ using sterile scissors. The homogenates were collected in DMEM (HyClone; GE Healthcare Life Sciences) supplemented with 20\% FBS (Gibco; Thermo Fisher Scientific, Inc.), $1 \%$ penicillin and $1 \%$ streptomycin (GENOM). The tumor cells were enriched with the differential adhesion technique (13) in the initial generations at $37^{\circ} \mathrm{C}$ under $5 \% \mathrm{CO}_{2}$, with the medium replaced every 2-3 days. The cells were passaged at 80-90\% confluence and FBS was decreased to $10 \%$ after 10 passages. The PDXPC1 cell line was obtained after $>80$ serial passages over a period of 2 years, and aliquots were frozen in liquid nitrogen.

Cell culture. The human pancreatic cancer cell line Panc-1 was purchased from the American Type Culture Collection and validated by comparing with a reference database of short tandem repeat (STR) profiles. The cells were maintained in DMEM supplemented with $10 \% \mathrm{FBS}$ at $37^{\circ} \mathrm{C}$ under $5 \% \mathrm{CO}_{2}$, and harvested using $0.25 \%$ trypsin and $0.02 \%$ EDTA (Gino Biopharmaceutical Technology).

Spheroid formation. Panc-1 or PDXPC1 cells were suspended in serum-free phenol red-free DMEM/F12 medium (Gibco; Thermo Fisher Scientific, Inc.) supplemented with 1X B27 (Invitrogen; Thermo Fisher Scientific, Inc.), $20 \mathrm{ng} / \mathrm{ml}$ human epidermal growth factor (Gibco; Thermo Fisher Scientific, Inc.), $10 \mathrm{ng} / \mathrm{ml}$ basic fibroblast growth factor (PeproTech, Inc.) and $5 \mu \mathrm{g} / \mathrm{ml}$ insulin (Novo Nordisk A/S), and seeded at a density of 200 cells/well in an ultralow attachment 6-well plate (Corning, Inc.). The cells were cultured for 7 days and spheres
$>50 \mu \mathrm{m}$ were counted under the Nikon ECLIPSE Ti inverted microscope (Nikon Corporation) (magnification, x200).

STR analysis. The STR profile of the PDXPC1 cell line was verified using the EX20 kit (AGCU ScienTech Incorporation) which allows for co-amplification of 20 STR loci, along with the amelogenin gender marker. The STR analysis of the PDXPC1 cell line was compared with known cell lines in the Deutsche Sammlung von Mikroorganismen und Zellkulturen (DSMZ) cell bank (https://www.dsmz.de).

Karyotyping. PDXPC1 cells at $80 \%$ confluence were incubated with $50 \mathrm{ng} / \mathrm{ml}$ Karyomax Colcemid (Thermo Fisher Scientific, Inc.) at $37^{\circ} \mathrm{C}$ for $24 \mathrm{~h}$. The cells were harvested and incubated with $0.075 \mathrm{M}$ hypotonic $\mathrm{KCl}$ solution at $37^{\circ} \mathrm{C}$ for $30 \mathrm{~min}$, and fixed in a 3:1 (v/v) mixture of methanol and acetic acid at $4^{\circ} \mathrm{C}$ for at least $1 \mathrm{~h}$. After dropping the fixed samples onto microscope slides, they were air dried and viewed under the Ikaros system (MetaSystems) with a bright-field microscope (Zeiss AG) (magnification, x1,000). At least five metaphases were counted per sample.

Generation of luciferase-overexpressing cells. Briefly, 30-40\% confluent PDXPC1 cells were transduced with a lentiviral vector containing pBR322 (CMV/Firefly luciferase/IRES/puromycin; Shanghai Genechem Co., Ltd.) at a multiplicity of infection of 10, along with $40 \mu \mathrm{l}$ HiTransG A solution (Shanghai Genechem Co., Ltd.) per $\mathrm{ml}$ infective solution. After $72 \mathrm{~h}$, the transduced and control PDXPC1 cells were harvested and re-seeded with $2 \mu \mathrm{g} / \mathrm{ml}$ puromycin (Shanghai Genechem Co., Ltd.) and expanded after $>2$ weeks. Luciferase-expressing PDXPC1 cells were confirmed by increased luminescence compared to control cells in the presence of $150 \mu \mathrm{g} / \mathrm{ml}$ D-luciferin potassium salt (MedChemExpress). The stably transduced PDXPC1 cells were examined 1-2 weeks before every experiment.

Establishment of cell line-derived xenograft model. All mouse experiments were approved by the Research Ethics Committee of the First Affiliated Hospital, College of Medicine, Zhejiang University. Panc-1 and PDXPC1 cells were suspended in PBS at a density of $1 \times 10^{7}$ cells $/ \mathrm{ml}$, and $200 \mu \mathrm{l}$ cell suspension was injected subcutaneously into the left armpit of each mouse. Tumor growth was monitored every 5 days, and tumor volumes were calculated using the formula [length $(\mathrm{mm}) \mathrm{x}$ width $\left.(\mathrm{mm})^{2}\right] / 2$. A total of 45 days after inoculation, the mice were sacrificed, and the tumors were harvested and fixed in $4 \%$ paraformaldehyde (Sangon Biotech Co., Ltd.) at room temperature for $24 \mathrm{~h}$. Pancreatic orthotopic injection was performed as previously described (14). Briefly, the PDXPC1 cells were infected with lentiviral vectors carrying the firefly luciferase reporter, and $50 \mu \mathrm{l}$ stably transduced cells $\left(1 \times 10^{7}\right.$ cells $\left./ \mathrm{ml}\right)$ were injected. Tumor growth was monitored twice a week for 6 weeks and the animals were sacrificed. For in vivo bioluminescence imaging, the mice were injected with D-luciferin potassium salt $(150 \mathrm{mg} / \mathrm{kg}$, i.p.; MedChemExpress), and anesthetized with isoflurane 15 min later. The concentrations of isoflurane used for inducing and maintaining the anesthetic state were 3 and $1.5 \%$, respectively. The intensity of the bioluminescence signal was measured for 1-60 sec using the In vivo 
Image system (PerkinElmer, Inc.), and analyzed using the Living Imaging software (PerkinElmer, Inc.; version 4.3.1). All mice were sacrificed by cervical dislocation during anesthesia (3\% isoflurane for induction, until the breathing had slowed) at the end of the experiments, or upon reaching other ethical endpoints (which did not occur throughout the study).

Histological and immunohistochemical staining (IHC). Fixed tumor tissues were embedded in paraffin, cut into 4- $\mu \mathrm{m}$ sections, and stained with hematoxylin and eosin (H\&E) at room temperature (5 min and $3 \mathrm{~min}$ incubation times, respectively) or further processed for IHC. The IHC was performed as previously described (15). Briefly, the tissue sections were first cleared with xylene and rehydrated using an ethanol gradient, incubated with $3 \% \mathrm{H}_{2} \mathrm{O}_{2}$ to quench the endogenous peroxidases, and then boiled in sodium citrate $(\mathrm{pH} 6)$ at $100^{\circ} \mathrm{C}$ for antigen retrieval. After blocking with $3 \%$ goat serum (Fdbio Science) for $1 \mathrm{~h}$ to reduce nonspecific binding, the sections were incubated overnight with the specific primary antibodies (Table $\mathrm{S} 1$ ) at $4^{\circ} \mathrm{C}$. The immunopositive signals were detected via a $20 \mathrm{~min}$ incubation at room temperature with an out-of-the-box biotinylated secondary antibody (cat. no. PV-8000; OriGene Technologies, Inc.) and $30 \mathrm{sec}$ incubation with the chromogen 3,3'-diaminobenzidine (cat. no. ZLI-9019; OriGene Technologies, Inc.) at room temperature. After counterstaining with hematoxylin for $3 \mathrm{~min}$ at room temperature, the slides were observed under the Leica DM4000 light microscope (magnification, x200; Leica Microsystems GmbH).

Whole exome sequencing (WES). DNA from PDXPC1 cells was extracted using QIAamp DNA Blood Mini kit (Qiagen $\mathrm{GmbH}$ ), according to the manufacturer's protocol, and assessed by $1 \%$ agarose gel electrophoresis visualized by gel-red (Sangon Biotech Co., Ltd.) staining. DNA libraries were prepared using the SureSelect Human All Exon V5/V6 kit (Agilent Technologies, Inc.) and were sequenced using the Illumina HiSeq X Ten instrument (Illumina, Inc.). The generated fastq files were matched with human reference genome version GRCh37 (hg19) using the Burrows-Wheeler Aligner (version 0.7.13) and Samblaster (version 0.1.22) (16,17). The insertions/deletions and single-nucleotide variations were detected using SAMtools (http://www.htslib.org; version 1.0) and annotated using ANNOVAR (http://annovar.openbioinformatics.org; version 2013, August 23). The raw data were uploaded to the Sequence Read Archive SRA database (https://www.ncbi.nlm.nih.gov/sra) in the National Center for Biotechnology Information (accession no. SRR9312601). To identify the cancer-related mutations, the filtering conditions were as follows: i) Mutations reported in the Catalogue of Somatic Mutations in Cancer (COSMIC) database (18), the rates of which in the 1,000 Genomes Project database (19) were $<0.1 \%$, which were not reported in the Exome Aggregation Consortium (ExAC) database (20); or ii) mutations not reported in the COSMIC and dbSNP (21) databases, the rates of which were $<0.1 \%$ in the ExAC database and $0.3 \%$ in the 1000 Genomes Project database.

Reverse transcription-quantitative $(R T-q) P C R$. Total RNA was extracted from cell lines using TRIzol ${ }^{\circledR}$ reagent (Invitrogen;
Table I. Clinical data for the donor patient.

\begin{tabular}{lc}
\hline Characteristics & Patient data \\
\hline Sex & Female \\
Age (years) & 70 \\
Histological diagnosis & $\begin{array}{c}\text { Pancreatic ductal } \\
\text { adenocarcinoma }\end{array}$ \\
Tumor size (cm) & $9.5 \times 5.5$ \\
Tumor number & 1 \\
TNM stage & IIA \\
Metastasis & No \\
Location & Body-tail \\
Level of tumor marker CA199 & 682.9 U/ml \\
History of chemotherapy & No \\
\hline
\end{tabular}

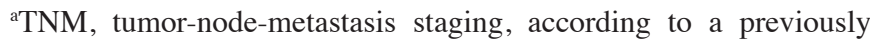
published system (46).

Thermo Fisher Scientific, Inc.), and cDNAs were synthesized from $0.5 \mu$ g total RNA using PrimeScript ${ }^{\mathrm{TM}}$ RT Master Mix (Takara Bio, Inc.), according to the manufacturer's instructions as follows: $37^{\circ} \mathrm{C}$ for $15 \mathrm{~min}$ and $85^{\circ} \mathrm{C}$ for $5 \mathrm{sec}$. qPCR was performed with a StepOnePlus Real-Time PCR system (Thermo Fisher Scientific, Inc.) using the TB Green ${ }^{\mathrm{TM}}$ Premix Ex Taq ${ }^{\mathrm{TM}}$ kit (Takara Bio, Inc.). qPCR was performed as follows: $95^{\circ} \mathrm{C}$ for $30 \mathrm{sec}$, then $40 \mathrm{cycles}$ of $95^{\circ} \mathrm{C}$ for $5 \mathrm{sec}$ and $60^{\circ} \mathrm{C}$ for $30 \mathrm{sec}$. The primers used for qPCR are listed in Table S2. The gene expression level was presented as the $\mathrm{Cq}$ value according to a previous study (22); $\geq 25$ was defined as negative expression and $<25$ as positive expression.

Western blot analysis. Cells were harvested and lysed using RIPA buffer (Sigma-Aldrich; Merck KGaA), and quantified using the Pierce ${ }^{\mathrm{TM}}$ BCA Protein Assay kit (Thermo Fisher Scientific, Inc.). A mass of $20 \mu \mathrm{g}$ protein per lane was separated by SDS-PAGE on a $10 \%$ gel, followed by immunoblotting (Immobilon P; EMD Millipore) with specific antibodies. The primary antibodies were incubated at $4{ }^{\circ} \mathrm{C}$ overnight and secondary antibodies were incubated at room temperature for $1 \mathrm{~h}$. The specific bands were detected using an enhanced chemiluminescence kit (Fdbio Science). The expression of $\beta$-actin served as the internal reference throughout the study. The antibodies are listed in Table S1.

Invasion and migration assays. In vitro invasion and migration were assessed by Transwell assays using membrane inserts of 8.0- $\mu \mathrm{m}$ pore size (Millicell; EMD Millipore) with or without Matrigel (Corning, Inc.) coating at $37^{\circ} \mathrm{C}$ for $1.5 \mathrm{~h}$. The harvested cells were seeded in the upper chamber at a density of $5 \times 10^{4}$ or $1 \times 10^{5}$ cells/well in $300 \mu 1$ serum-free medium. The lower chamber was filled with $700 \mu \mathrm{l}$ complete DMEM (10\% FBS). The inserts were fixed with 95\% ethanol at room temperature for $15 \mathrm{~min}$, stained with $0.1 \%$ crystal violet (Sigma-Aldrich; Merck KGaA) at room temperature for $15 \mathrm{~min}$ and imaged after $24 \mathrm{~h}$ of culture. The numbers of migratory/invasive cells were counted in five random fields 

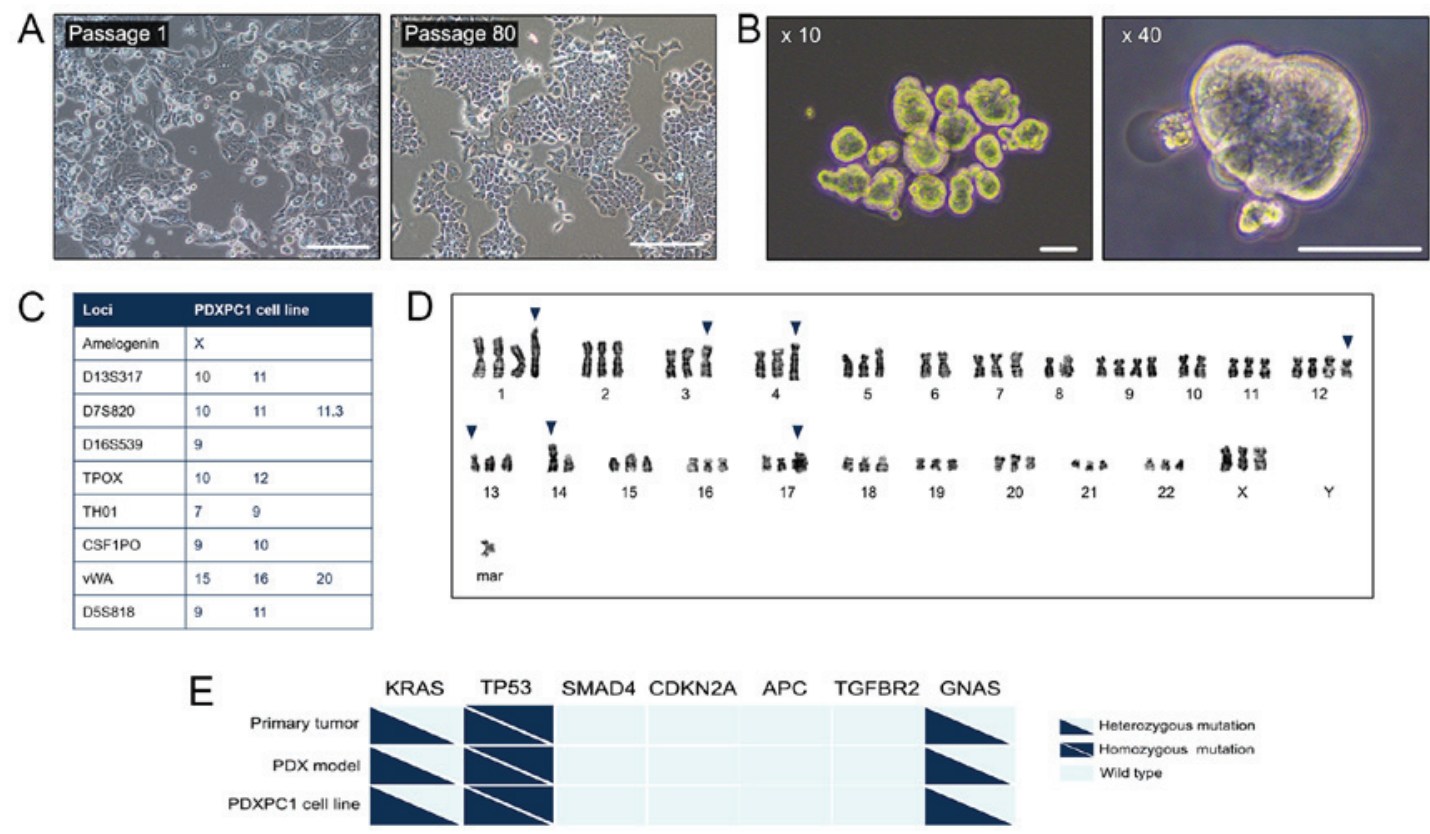

Figure 1. Establishment of the PDXPC1 cell line. (A) Representative images of PDXPC1 cells at passage 1 (left) and passage 80 (right). Scale bar, $200 \mu \mathrm{m}$. (B) Representative images of PDXPC1 spheroids at x10 (left) and x40 (right) magnification. Scale bar, $50 \mu \mathrm{m}$. (C) The STR profile of the PDXPC1 cell line. In order to protect the identity of the donor, only listed the 8 core STR loci plus amelogenin are listed. (D) Representative aneuploidy images of PDXPC1 metaphases with chromosome number 69. The representative karyotype of PDXPC1 was: $69, \mathrm{XXX},+1, \operatorname{der}(1) \mathrm{t}(1 ; 2)(\mathrm{p} 11 ; \mathrm{q} 11.1)$, der(3)t( $3 ; 10)(\mathrm{p} 13 ; \mathrm{p} 11.2)$, add(4) (q35), -6, -8, +9, -10,+12, del(12)(q24.2), der(13)t(13;17)(p10;q10), -14, rob(14;14)(q10;q10), der(17)t(17;?)(q12;?), +mar. The blue arrows indicate the abnormalities. (E) Genetic mutations in the primary tumor, PDX model and PDXPC1 cell line. Triangles and squares indicate heterozygous and homozygous mutations respectively, and wild type is shown as light blue. CDKNA2A, cyclin-dependent kinase inhibitor 2A; APC, APC regulator of WNT signaling pathway; TGFBR2, transforming growth factor receptor $\beta 2$; GNAS, GNAS complex locus; TP53, tumor protein $\mathrm{p} 53$.

at x200 magnification under a Nikon ECLIPSE Ti inverted microscope (Nikon Corporation).

Flow cytometry analysis. Cell suspensions were harvested and stained with anti-CD44-FITC (BD Biosciences; cat. no. 560977) and FITC-isotype negative control (BD Biosciences; cat. no. 556655) for $30 \mathrm{~min}$ at $4^{\circ} \mathrm{C}$ in the dark. Flow cytometry was performed on a BD FACS Canto II (BD Biosciences), and data were analyzed using FlowJo software (FlowJo, LLC; version 10.0.7). Annexin V-FITC and propidium iodide-phycoerythrin staining was performed to detect apoptotic cells, according to the manufacturer's protocol (BD Biosciences). The apoptotic rate was calculated as the percentage of early and late apoptotic cells in total cells.

Drug screening. Panc-1 and PDXPC1 cell lines were plated in 96-well plates with 3,000 cells/well, and treated with a concentration gradient of each compound for $24 \mathrm{~h}$. After 48 or $72 \mathrm{~h}$ of incubation, cell viability was assessed using the Cell Counting Kit-8 (Dojindo Molecular Technologies, Inc.). The $\mathrm{IC}_{50}$ was calculated via the Bliss method (23). Target drugs for screening were found via the United States Food and Drug Administration (USFDA; https://www.fda.gov/drugs/development-approvalprocess-drugs/drug-approvals-and-databases), Drug Bank (https://www.drugbank.ca/) and MycancerGenome (https://www.mycancergenome.org/) databases based on somatic mutations of PDXPC1. The concentration ranges of each compound are listed in Table S3, and were selected for each compound based on published literature (24) as well as the authors' previous in vitro data (Du et al, unpublished).
Statistical methods. Statistical analyses were performed using GraphPad Prism 7.0 Software (GraphPad Software, Inc.), and data are presented as the mean \pm SEM. Unpaired t-tests were used to evaluate the difference between two groups, and multiple groups were compared by one-way ANOVA with the Tukey post hoc test. $\mathrm{P}<0.05$ was considered to indicate a statistically significant difference. Each experiment was repeated at least three times.

\section{Results}

PDXPC1 cell line, established from PDX models, retains the mutagenic signature of the original tumor. The primary culture of PDAC cells was from a PDAC PDX model. The clinical features of the PDAC patient are listed in Table I. The PDAC cells grew consistently over a period of 2 years and maintained their morphology (Fig. 1A). After 80 stable passages, this permanent PDAC cell line was designated PDXPC1, and frozen for subsequent analysis. The spheroid morphology of PDXPC1 is shown in Fig. 1B, indicating a cancer stem cell phenotype. The STR analysis of this cell line indicated no matches to any of the cell lines deposited in the DSMZ cell bank (Fig. 1C). The PDXPC1 cells exhibited aneuploidy resulting in chromosomal numbers between 68 and 70 (Fig. 1D), which was consistent with the hypothesis that tumorigenesis is typically accompanied by a high degree of aneuploidy (25). To examine the consistency with the original tumor tissue and PDX, an oncogenic mutation screen of seven genes involved in PDAC progression (26) was first performed, and the results showed that the $\mathrm{KRAS}^{\mathrm{G} 12 \mathrm{~V}}$, tumor protein $\mathrm{p} 53$ 

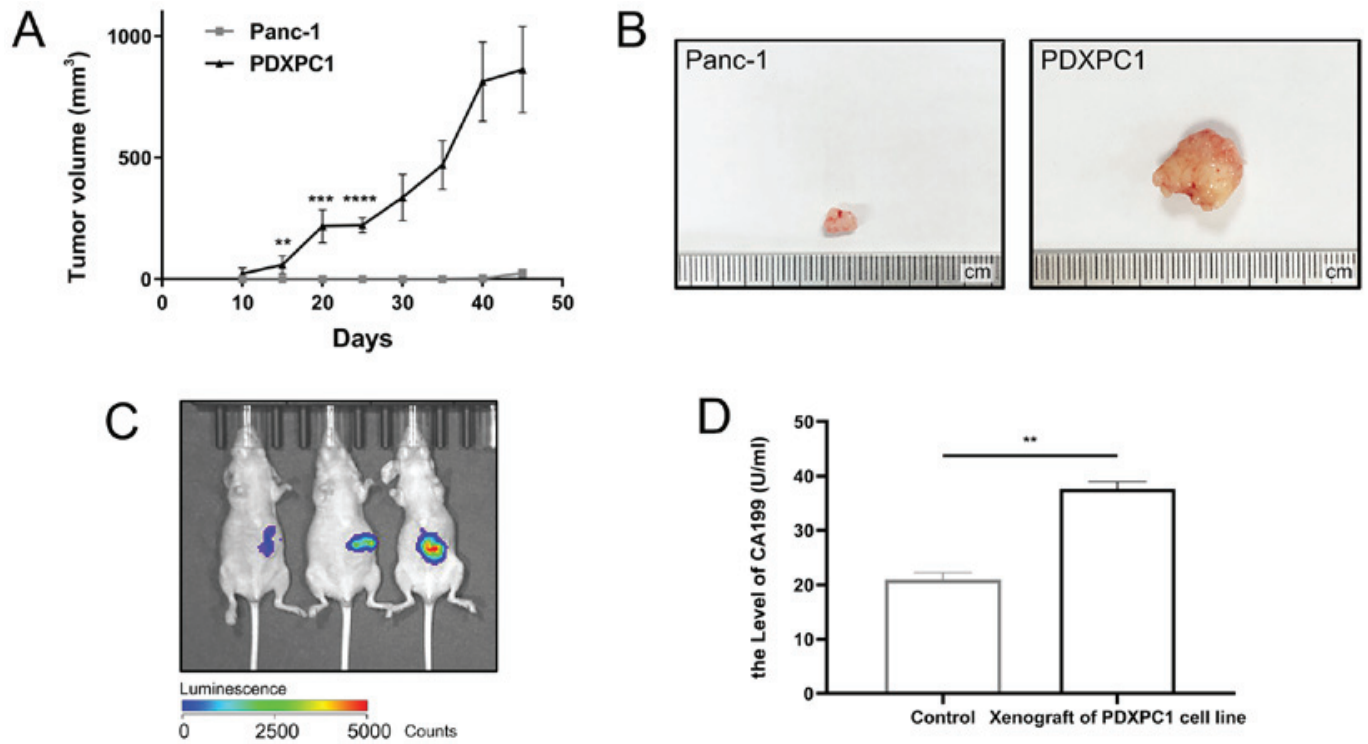

Figure 2. PDXPC1 tumor growth in immunodeficient mice. (A) The growth of subcutaneous PDXPC1 and Panc-1 xenografts was measured every 5 days for 45 days. ${ }^{* *} \mathrm{P}<0.01 ;{ }^{* * * *} \mathrm{P}<0.001 ;{ }^{* * * * *} \mathrm{P}<0.0001$ vs. respective Panc-1 group. (B) Representative images of subcutaneous xenografts generated from PDXPC1 (right) and Panc-1 (left) cell lines. (C) Representative in vivo fluorescence imaging of orthotopic xenografts generated from PDXPC1. (D) Serum levels of CA199 $(\mathrm{U} / \mathrm{ml})$ in the peripheral blood of normal and PDXPC1 tumor-bearing mice. ${ }^{* *} \mathrm{P}<0.01$.

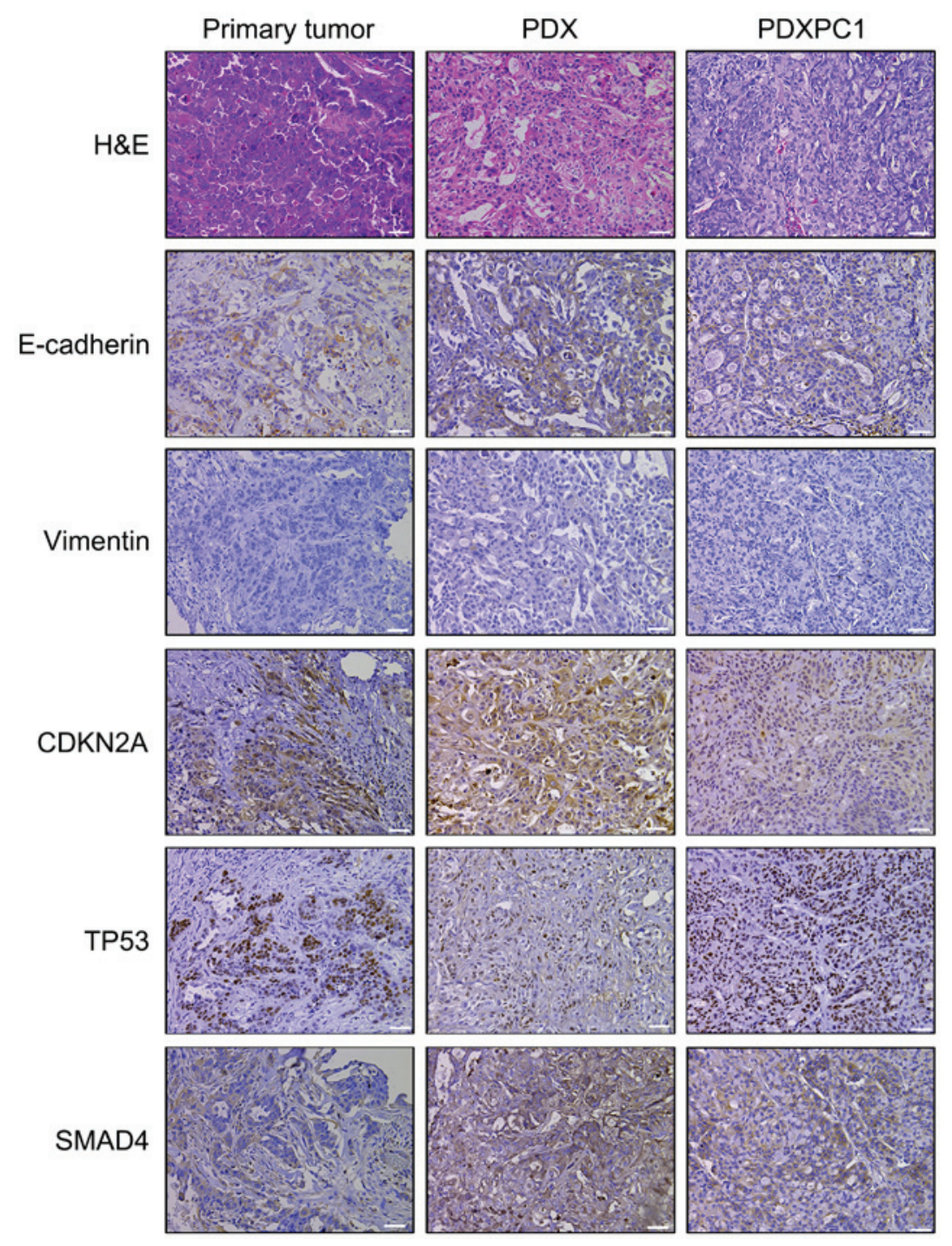

Figure 3. Representative H\&E and immunohistochemical images of PDXPC1-derived xenografts. Scale bar, $50 \mu \mathrm{m}$. H\&E, hematoxylin and eosin; TP53, tumor protein p53; CDKNA2A, cyclin-dependent kinase inhibitor 2A; PDX, patient-derived xenograft. 
A

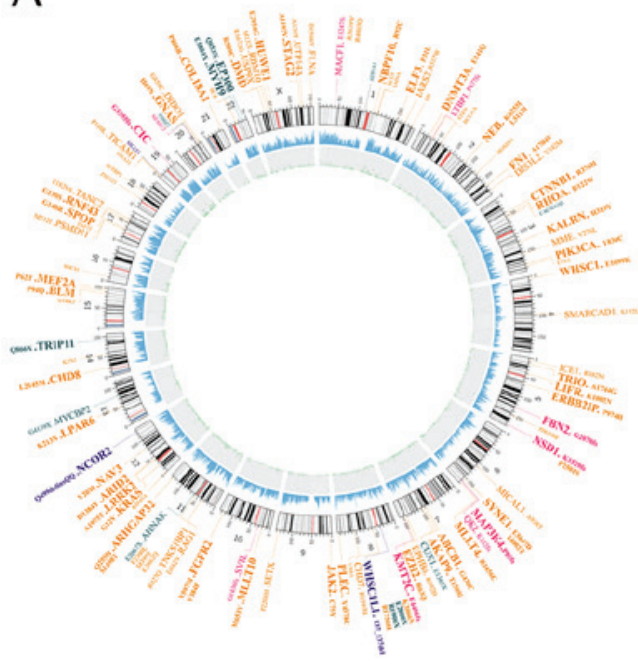

$\mathrm{B}$

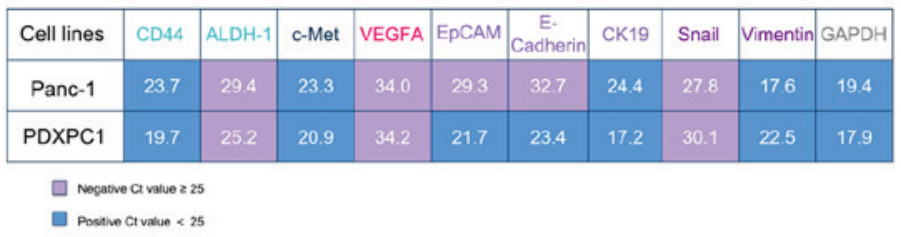

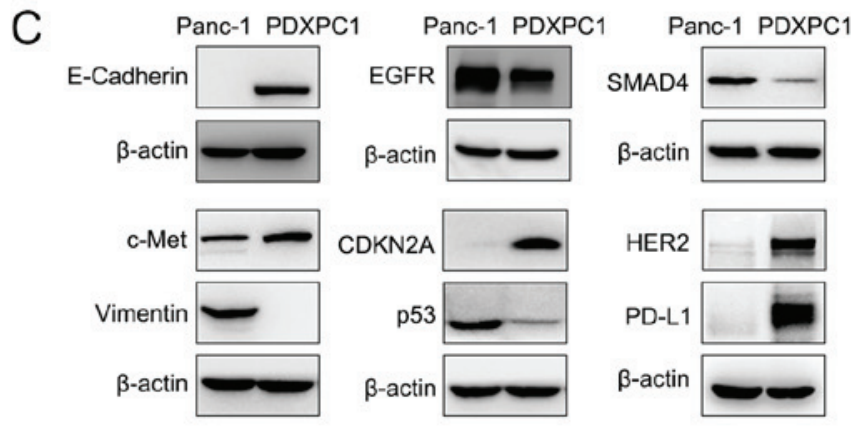

D
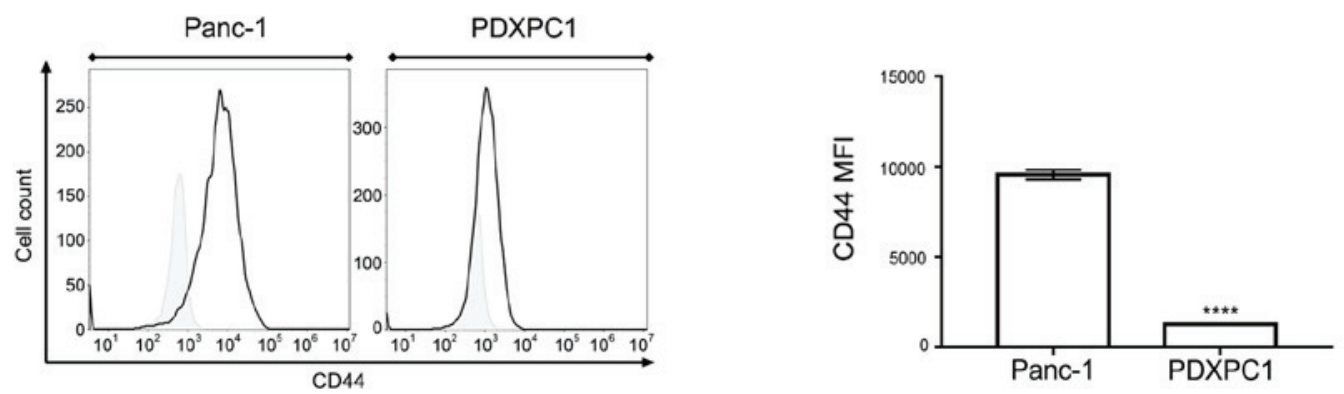

Figure 4. Molecular characterization of the PDXPC1 cell line. (A) Circos plot of somatic mutations of PDXPC1 cells. The outer ring indicates the driver gene mutations (orange, missense mutation; fuchsia, frame shift deletion; dark blue, in-frame insertion; and dark green, nonsense mutation), and the subsequent rings indicate the chromosomes, sequencing coverage and the frequency of single-nucleotide variations and insertions-deletions, each indicated by the size of the dots. (B) Differential mRNA expression levels of PDXPC1 and Panc-1, with GAPDH as the control. Cq values are presented as the mean \pm SD of three independent experiments. $\mathrm{Cq}<25$ indicates positive expression. (C) Phenotypic characterization of the PDXPC1 cell line by western blotting. $\beta$-actin was used as the reference control. (D) CD44 expression level in PDXPC1 and Panc-1 cell lines, as assessed by flow cytometry. Left, Histogram of CD44 expression level in Panc-1 and PDXPC1 cell lines. Right, rCD44 mean fluorescence index of Panc-1 and PDXPC1 cell lines; ${ }^{* * * *} \mathrm{P}<0.0001$ vs. Panc-1. CDKNA2A, cyclin-dependent kinase inhibitor 2A; EGFR, epidermal growth factor receptor; ALDH-1, aldehyde dehydrogenase 1; VEGFA, vascular endothelial growth factor A; EpCAM, epithelial cell adhesion molecule; CK19, keratin 19.

(TP53) $^{\mathrm{R} 155 \mathrm{H}}$ and GNAS complex locus (GNAS) ${ }^{\mathrm{H} 69 \mathrm{~N}}$ mutations were common between the primary patient tumor, PDX and PDXPC1 (Fig. 1E), while the remaining genes were wild-type. Thus, the PDXPC1 cell line retained the mutagenic signature of the original tumor.

PDXPC1 cell line induces rapid in vivo tumor growth and maintains a similar histomorphology and immunophenotype to the original tumor. To evaluate the potential tumorigenic ability of the PDXPC1 cells, PDXPC1 cells in comparison with a commercial pancreatic cancer cell line, Panc-1 were subcutaneously injected into immunodeficient mice. As shown in Fig. 2A, PDXPC1 cells resulted in aggressive tumor growth that exceeded $10 \%$ of the body weight within 45 days of inoculation. By contrast, Panc-1 tumor growth was very slow, and only palpable nodes were detected (Fig. 2B). To simulate the tumor microenvironment more accurately, luciferase-labeled PDXPC1 cells were transplanted into the murine pancreas, and tumors were detected after 15 days using an in vivo imaging system (Fig. 2C). Since the patient donor of the PDXPC1 cell line had elevated serum levels of CA199, a circulating diagnostic biomarker of PDAC (27), the peripheral sera of the tumor-bearing and control mice was analyzed and high levels of CA199 were detected in the former (Fig. 2D). H\&E staining confirmed similar histomorphology between the PDXPC1-derived xenografts, patient-derived xenografts and the primary tumor (Fig. 3). In addition, E-cadherin and vimentin immunostaining showed that PDXPC1 cells maintained their epithelial nature. These three samples were also positive for cyclin-dependent kinase inhibitor 2A (CDKN2A or p16), TP53 and SMAD4, all of which are inactivated in early pancreatic carcinogenesis (28). Taken together, the PDXPC1 cell line maintained the key characteristics of the original tumors.

PDXPC1 cell line maintains its epithelial origin and carries overexpression of HER2, CDKN2A and programmed cell death 1 ligand 1 (PD-L1). WES of the PDXPC1 cell line was performed to fully characterize the PDXPC1 cells. Since the mutational data of matched normal tissues was lacking, the non-mutational polymorphisms were first excluded using public databases, and the remaining polymorphisms were filtered through the COSMIC database to identify the cancer-related mutations. The driver mutations were specifically searched for 

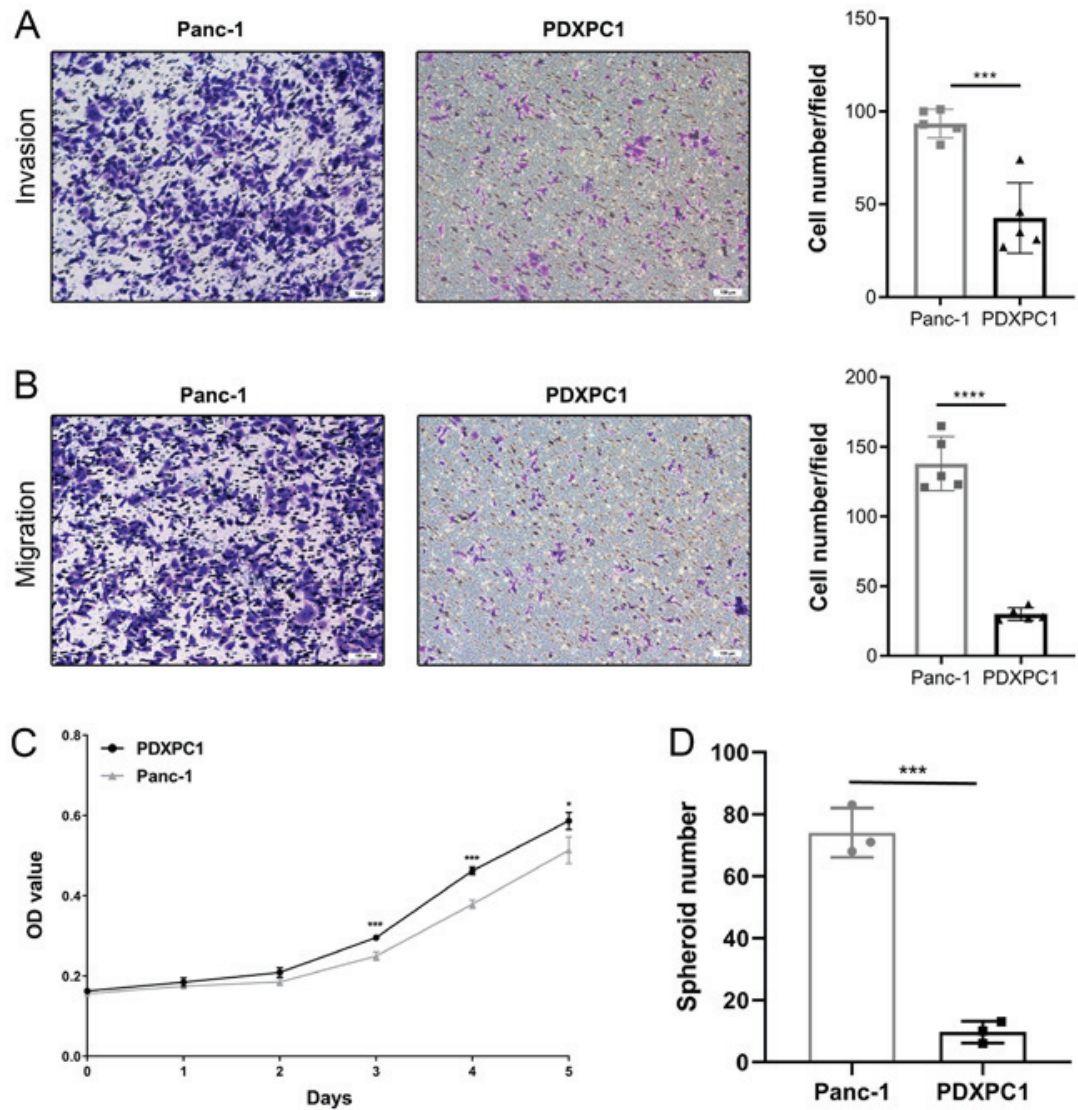

Figure 5. PDXPC1 cell line exhibits relatively mild biological behaviors. (A) Migration assay of the PDXPC1 and Panc-1 cell lines. ${ }^{* * * *} \mathrm{P}<0.001$. (B) Invasion assay of the PDXPC1 and Panc-1 cell lines; ${ }^{* * * * *} \mathrm{P}<0.0001$. (C) In vitro growth curves of the PDXPC1 and Panc-1 cell lines. ${ }^{*} \mathrm{P}<0.05$; ${ }^{* * * *} \mathrm{P}<0.001$ vs. respective Panc-1 group. (D) Statistical analysis of spheroid number in the PDXPC1 and Panc-1 cell lines. ${ }^{* * *} \mathrm{P}<0.001$. Scale bars, $100 \mu \mathrm{m}$. OD, optical density.

using publicly available databases, and of the four commonly mutated genes in PDAC (29), KRAS ${ }^{\mathrm{G} 12 \mathrm{~V}}$ was detected in the PDXPC1 cell line. In addition, other genes that are mutated in PDAC [such as GNAS, catenin $\beta 1$ (CTNNB1), ring finger protein 43 and fibroblast growth factor receptor 2] and some other cancer types (e.g., chromodomain helicase DNA binding protein 8, phosphatidylinositol-4,5-bisphosphate 3-kinase catalytic subunit- $\alpha$, myosin heavy chain 9 and stromal antigen 2) (30-33) were also identified in the established cell lines (Fig. 4A).

Then, to fully characterize the PDXPC1 cell line, the mRNA expression level of some genes of interest, shown in Fig. 4B, was tested. The expression levels of various epithelial and mesenchymal markers in the PDXPC1 cell line were compared with the Panc-1 cell line, and it was found that while the PDXPC1 cells expressed high levels of the epithelial markers (E-cadherin, EpCAM and keratin 19) and low levels of mesenchymal marker vimentin, Panc-1 expressed vimentin. Furthermore, the PDXPC1 cells expressed the proto-oncogene c-Met and the cancer stem cell markers CD44 and ALDH1, which have been previously detected in PDAC (34). Next, protein expression levels were examined using different methods to identify the phenotype of the PDXPC1 cell line. The epithelial nature of the PDXPC1 cell line, as well as highly expressed c-Met, were consistent with the mRNA expression level results (Fig. 4B). HER2 and EGFR, which are related to pancreatic tumor progression $(35,36)$ were also highly expressed (Fig. 4C). The presence of CDKN2A,
TP53 and SMAD4 was consistent with the IHC results of the PDXPC1-derived xenograft. Since the PDXPC1 cells expressed higher levels of CD44 mRNA compared to Panc-1, the relative CD44 protein levels were subsequently examined by flow cytometry. CD44 protein levels were lower in the PDXPC1 cell line (Fig. 4D). Since early trials of single-agent immune checkpoint blockade therapy have not shown encouraging results $(37,38)$, the expression of PD-L1 in PDXPC1 cells was also examined, and aberrantly high levels were observed. Taken together, the fully characterized PDXPC1 cell line is a suitable model to study PDAC genesis.

PDXPC1 cell line exhibits relatively mild biological behaviors. Next, the biological behaviors of the PDXPC1 cell line were analyzed. The migration and invasion ability of PDXPC1 cells were evaluated, and the results indicated that the PDXPC1 cell line exhibited a lower migration and invasion potential than the Panc-1 cell line (Fig. 5A and B). Fig. 5C shows the in vitro growth curve of PDXPC1 cells. Different from the in vivo tumorigenesis study, the growth rate was similar between PDXPC1 and Panc-1 cell lines. The doubling time of the PDXPC1 and Panc-1 cell lines was 37.2 and 39.9 h, respectively. Considering the different expression pattern of CD44, the cancer stem cell marker, at the transcriptional and protein level the spheroid assay was performed on the PDXPC1 and Panc-1 cell lines. The result showed a lower spheroid formation rate of PDXPC1 cells compared to that of Panc-1 cells, which was consistent with the protein expression level data (Fig. 5D). 

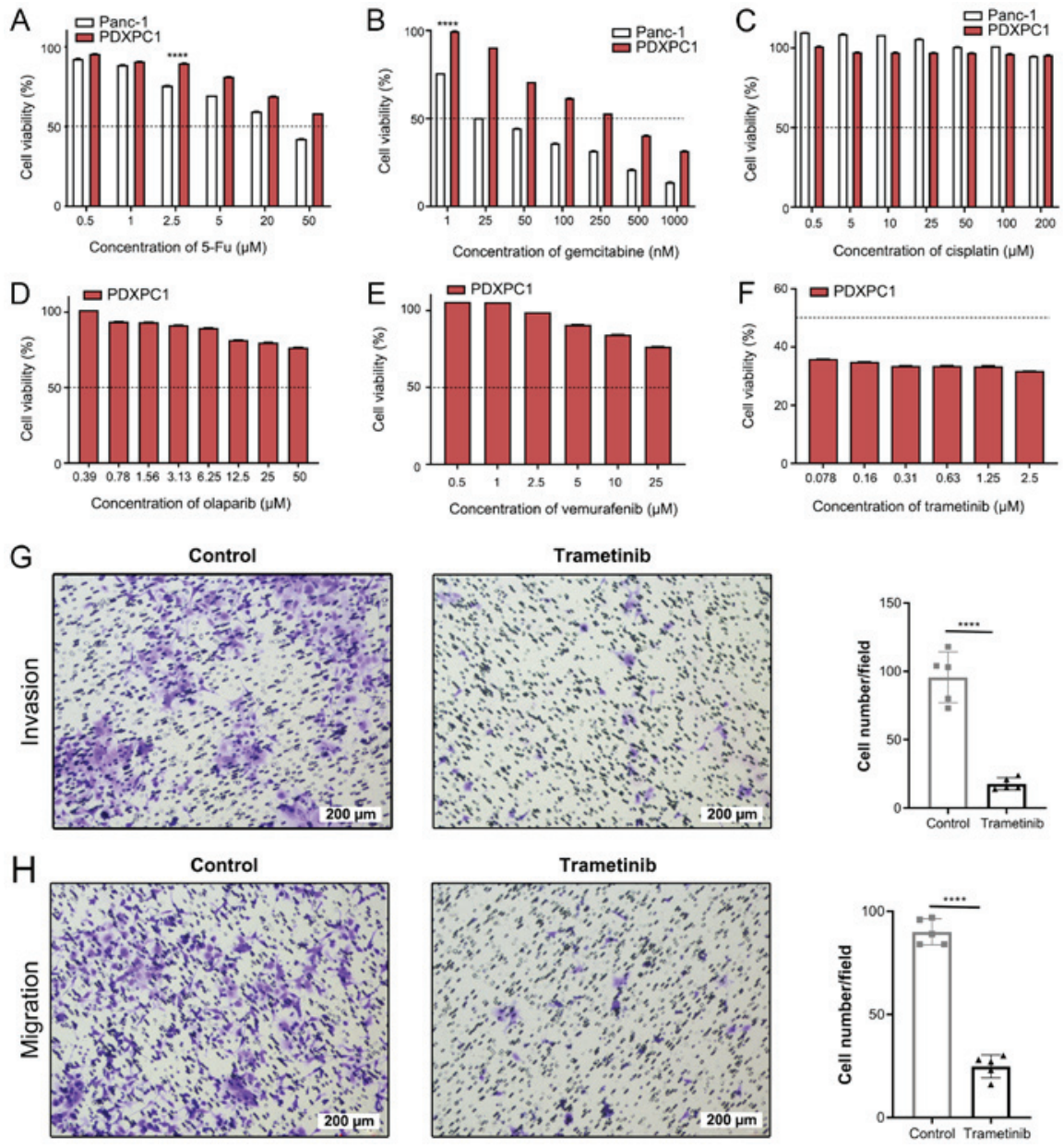

Figure 6. Sensitivity of the PDXPC1 cell line to multiple drugs. CCK-8 assay results showing the percentage of viable PDXPC1 and Panc-1 cells after treatment with (A) 5-Fu, (B) gemcitabine and (C) cisplatin. ${ }^{* * * *} \mathrm{P}<0.0001$ vs. respective Panc-1 group. Response of PDXPC1 cells to (D) olaparib, (E) vemurafenib and (F) trametinib. The dotted lines indicate 50\% viability. (G) Invasion assay of control and trametinib-treated PDXPC1 cells. (H) Migration assay of control and trametinib-treated PDXPC1 cells. Scale bar, $200 \mu \mathrm{m} .{ }^{* * * *} \mathrm{P}<0.0001 .5-\mathrm{Fu}, 5$-fluorouracil.

A

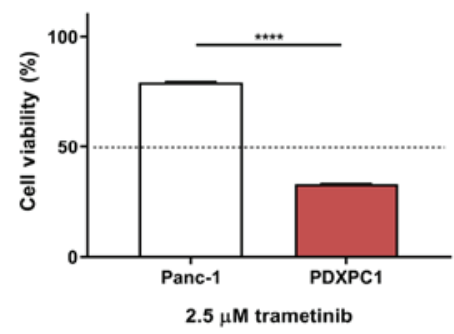

B

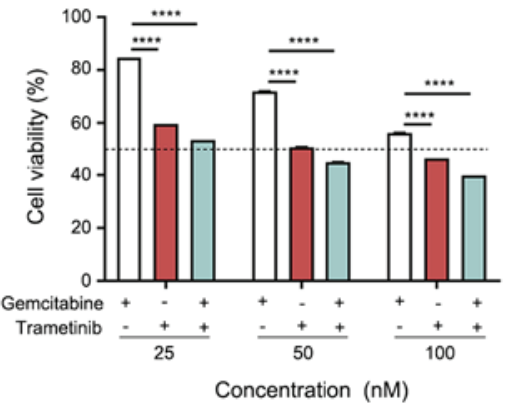

C Gemcitabine - + - + +

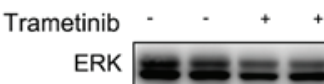

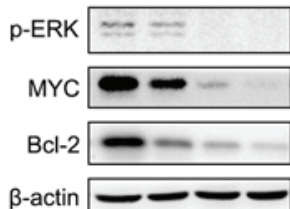

D
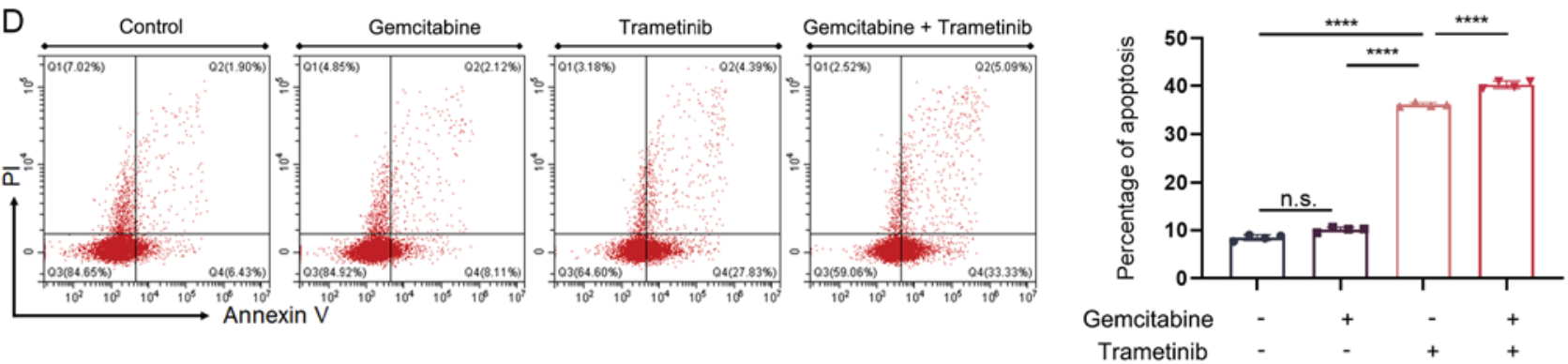

Figure 7. Trametinib inhibits the growth of PDXPC1 cells by inducing cell apoptosis via Bcl-2 inactivation. (A) Cell viability of PDXPC1 and Panc-1 cells following treatment with $2.5 \mu \mathrm{m}$ trametinib. (B) Cell viability of PDXPC1 cells following treatment with gemcitabine and/or trametinib. The dotted lines indicate 50\% viability. (C) Immunoblotting showing the expression levels of ERK, pERK, MYC and Bcl-2 after gemcitabine and/or trametinib treatment. (D) Percentage of apoptotic PDXPC1 cells as detected by Annexin V/PI staining. ${ }^{* * * *} \mathrm{P}<0.0001$; n.s., not significant. PI, propidium iodide. 
PDXPC1 cell line is resistant to multiple therapeutic drugs excluding trametinib, a MEK inhibitor. To determine the utility of PDXPC1 as a suitable model for screening anti-PDAC drugs, the cells were treated with gemcitabine, 5-fluoruracil (5-Fu) and cisplatin (Fig. 6A-C), which are routinely used in the clinical management of PC. Both cell lines were resistant to the DNA cross-linker cisplatin. While Panc-1 was sensitive to gemcitabine and 5-Fu within the doses used, PDXPC1 only responded to gemcitabine at high concentration levels. The PDXPC1 cell line showed a drug-resistant phenotype according the $\mathrm{IC}_{50}$ of gemcitabine $(275.1 \pm 1.50$ vs. $22.2 \pm 1.25 \mathrm{nM}$; 12.39-fold difference).

Therefore, other target drugs were screened based on the somatic mutational profile of PDXPC1 on online drug databases, including USFDA, Drug Bank and MycancerGenome. The database of MycancerGenome indicated that poly-ADP ribose polymerase (PARP) inhibitors, BRAF inhibitors and MEK inhibitors may be the target drugs for PDXPC1 cells with CTNNB1 mutations. Further drug screening showed that PDXPC1 cell line was resistant to the PARP inhibitor olaparib (Fig. 6D) and the BRAF inhibitor vemurafenib (Fig 6E), but responded to the MEK inhibitor trametinib (Fig. 6F). Furthermore, trametinib-treated PDXPC1 cells showed significantly decreased invasion and migration $(\mathrm{P}<0.0001$; Fig. 6G and $\mathrm{H}$ ). These results indicated that MEK is a therapeutic target in the PDXPC1 cell line.

By contrast, the CTNNB1-wild type Panc-1 cells were unresponsive to trametinib (Fig. 7A). The combination of low-dose trametinib and gemcitabine significantly inhibited the PDXPC1 cells (Fig. 7B), suggesting the possibility of other efficient combination treatments with trametinib. Mechanistically, trametinib, but not gemcitabine, reduced the expression of p-ERK, MYC and the pro-survival Bcl-2 protein (Fig. 7C). Thus, trametinib decreased PDXPC1 cell proliferation by activating the apoptotic pathway via $\mathrm{Bcl}-2$ degradation, which was confirmed by the significantly increased apoptosis rates seen after treatment with trametinib and trametinib together with gemcitabine, but not with gemcitabine alone (Fig. 7D). Taken together, the overall drug screening results indicated that a subset of PDAC patients could benefit from a MEK inhibitor in the therapeutic regimen.

\section{Discussion}

The poor prognosis of PDAC is partly attributed to its chemoresistance. Gemcitabine-based monotherapy or combination treatments have been largely unsatisfactory in the majority of patients with PDAC (5). PDXs closely replicate the clinical characteristics of the tumors and are therefore indispensable for accurate preclinical drug evaluation. However, cancer cell lines are preferable for molecular studies and high-throughput drug screenings. The present study established a new stable pancreatic cancer cell line, PDXPC1, from a PDAC PDX, since it was not possible to establish a cancer cell line directly from a primary tumor sample. The results demonstrated that the PDXPC1 cell line fully recapitulated the primary tumor and provided a suitable tool for exploring the molecular basis of PDAC. Furthermore, the specific responsiveness to the small molecular inhibitors tested based on mutation information, and the involvement of signaling pathways, indicated a potential novel therapeutic approach for a subgroup of PDAC patients.

The target drug screening revealed that the PDXPC1 cell line, with a CTNNB1 mutation, may be susceptible to three directed therapies, including BRAF, PARP and MEK inhibitors. However, in vitro drug sensitivities showed that PDXPC1 cells were only response to trametinib, a small molecular compound which specifically inhibits MEK $1 / 2$. CTNNB1, the gene encoding $\beta$-catenin, is a key transcriptional activator of the $\mathrm{Wnt} / \beta$-catenin signaling pathway that is oncogenic in most human cancer types (39). Mutant CTNNB1 has been implicated in the pathogenesis of several cancer types, including melanoma, colorectal cancer, hepatocellular carcinoma and pancreatic solid-pseudopapillary tumor (40). Few relevant studies have been conducted in pancreatic disorders, to the best of our knowledge. The present study evaluated the inhibitory effect of trametinib in the Panc-1 cell line, carrying wild-type CTNNB1, confirming that the CTNNB1 mutation might be a target molecular marker for trametinib treatment in PDAC. Plans for next stage may involve a large number of PDAC cell lines and targeted CTNNB1 gene editing to further confirm these conclusions.

The MEK-ERK pathway plays an important role in cancer cell proliferation, migration and chemoresistance (41), and is constitutively activated in $>90 \%$ of PC cases, wherein it drives KRAS-dependent tumor growth and decreases the survival rate (42). The intricate crosstalk between the $\mathrm{Wnt} / \beta$-catenin and mitogen-activated protein kinase (MAPK) pathways has been reported in melanoma and colorectal cancer. In melanoma, studies found that inhibition of the MAPK pathway resulted in enhanced Wnt/ $\beta$-catenin signaling, which induced the reduction of tumor size due to apoptosis $(43,44)$. By contrast, Wnt/ $\beta$-catenin and MAPK signaling synergistically promoted cancer development in colon cancer (45). It appears that the relationship between $\mathrm{Wnt} / \beta$-catenin is dependent on the specific context, which will be investigated in future work.

The poor prognosis of PDAC is partly attributed to its chemoresistance. Gemcitabine based monotherapy or combination treatments have been largely unsatisfactory in the majority of patients with PDAC. The PDXPC1 cell line was susceptible to MEK inhibitor-based monotherapy, resulting in ERK inactivation and Bcl-2 degradation. Therefore, a subset of PDAC patients may benefit from MEK inhibition treatment.

\section{Acknowledgements}

Not applicable.

\section{Funding}

This research was funded by the National Natural Science Foundation of China (grant no. 81772853), Zhejiang Science and Technology Project (grant no. 2017C37171) and the Natural Science Foundation of Zhejiang (grant no. LZ16H160001).

\section{Availability of data and materials}

The datasets used and/or analyzed during the current study are available from the corresponding author on reasonable request. 


\section{Authors' contributions}

LST conceived the study. JZ and MK performed the karyotyping and IHC experiments. KFH, XXD, YYH and ZZX performed experiments. XXD analyzed the data and performed the statistical analysis, as well as writing the original draft. $\mathrm{KFH}, \mathrm{JC}$, JZ and LST reviewed and edited the manuscript. LST and KFH obtained funding support.

\section{Ethics approval and consent to participate}

The study was approved by the Ethical Review Committee of The First Affiliated Hospital of Zhejiang University School of Medicine, and written informed consent was obtained from the patient. All mouse experiments were approved by the Research Ethics Committee of the First Affiliated Hospital, College of Medicine, Zhejiang University.

\section{Patient consent for publication}

Not applicable.

\section{Competing interests}

The authors declare that they have no competing interests.

\section{References}

1. Wolfgang CL, Herman JM, Laheru DA, Klein AP, Erdek MA, Fishman EK and Hruban RH: Recent progress in pancreatic cancer. CA Cancer J Clin 63: 318-348, 2013.

2. Zhang G, He P, Tan H, Budhu A, Gaedcke J, Ghadimi BM, Ried T, Yfantis HG, Lee DH, Maitra A, et al: Integration of metabolomics and transcriptomics revealed a fatty acid network exerting growth inhibitory effects in human pancreatic cancer Clin Cancer Res 19: 4983-4993, 2013.

3. Kamisawa T, Wood LD, Itoi T and Takaori K: Pancreatic cancer Lancet 388: 73-85, 2016.

4. Ryan DP, Hong TS and Bardeesy N: Pancreatic adenocarcinoma. N Engl J Med 371: 1039-1049, 2014.

5. Heinemann V, Wilke H, Mergenthaler HG, Clemens M, König H, Illiger HJ, Arning M, Schalhorn A, Possinger K and Fink U: Gemcitabine and cisplatin in the treatment of advanced or metastatic pancreatic cancer. Ann Oncol 11: 1399-1403, 2000.

6. Michl P and Gress TM: Current concepts and novel targets in advanced pancreatic cancer. Gut 62: 317-326, 2013.

7. Fusenig NE, Capes-Davis A, Bianchini F, Sundell S and Lichter P: The need for a worldwide consensus for cell line authentication: Experience implementing a mandatory requirement at the International Journal of Cancer. PLoS Biol 15: e2001438, 2017.

8. Ye F, Chen C, Qin J, Liu J and Zheng C: Genetic profiling reveals an alarming rate of cross-contamination among human cell lines used in China. FASEB J 29: 4268-4272, 2015.

9. Dangles-Marie V, Pocard M, Richon S, Weiswald LB, Assayag F, Saulnier P, Judde JG, Janneau JL, Auger N, Validire P, et al: Establishment of human colon cancer cell lines from fresh tumors versus xenografts: Comparison of success rate and cell line features. Cancer Res 67: 398-407, 2007.

10. Bissig-Choisat B, Kettlun-Leyton C, Legras XD, Zorman B, Barzi M, Chen LL, Amin MD, Huang YH, Pautler RG Hampton OA, et al: Novel patient-derived xenograft and cell line models for therapeutic testing of pediatric liver cancer. J Hepatol 65: 325-333, 2016.

11. Wang H, Lu J, Tang J, Chen S, He K, Jiang X, Jiang W and Teng L: Establishment of patient-derived gastric cancer xenografts: A useful tool for preclinical evaluation of targeted therapies involving alterations in HER-2, MET and FGFR2 signaling pathways. BMC Cancer 17: 191, 2017.
12. Xu X, Qian L-J, Su X-Y, He KF, Jin KT, Gu LH, Feng JG, Li GL, Zhou Q, Xu ZZ, et al: Establishment and characterization of GCSR1, a multi-drug resistant signet ring cell gastric cancer cell line. Int J Oncol 46: 2479-2487, 2015.

13. Nikkhah M, Strobl JS, Peddi B and Agah M: Cytoskeletal role in differential adhesion patterns of normal fibroblasts and breast cancer cells inside silicon microenvironments. Biomed Microdevices 11: 585-595, 2009.

14. Kim MP, Evans DB, Wang H, Abbruzzese JL, Fleming JB and Gallick GE: Generation of orthotopic and heterotopic human pancreatic cancer xenografts in immunodeficient mice. Nat Protoc 4: 1670-1680, 2009.

15. Du X, Wu L, Ur Rahman MS, Teng X, Teng L, Ye J and Cao J: Promoter Hypomethylation Is Responsible for Upregulated Expression of HAI-1 in Hepatocellular Carcinoma. Dis Markers 2019: 9175215, 2019.

16. Li H and Durbin R: Fast and accurate short read alignment with Burrows-Wheeler transform. Bioinformatics 25: 1754-1760, 2009.

17. Faust GG and Hall IM: SAMBLASTER: Fast duplicate marking and structural variant read extraction. Bioinformatics 30 : 2503-2505, 2014.

18. Li MM, Datto M, Duncavage EJ, Kulkarni S, Lindeman NI, Roy S, Tsimberidou AM, Vnencak-Jones CL, Wolff DJ, Younes A, et al: Standards and Guidelines for the Interpretation and Reporting of Sequence Variants in Cancer: A Joint Consensus Recommendation of the Association for Molecular Pathology, American Society of Clinical Oncology, and College of American Pathologists. J Mol Diagn 19: 4-23, 2017.

19. Abecasis GR, Altshuler D, Auton A, Brooks LD, Durbin RM, Gibbs RA, Hurles ME and McVean GA; 1000 Genomes Project Consortium: A map of human genome variation from population-scale sequencing. Nature 467: 1061-1073, 2010.

20. Karczewski KJ, Weisburd B, Thomas B, Solomonson M, Ruderfer DM, Kavanagh D, Hamamsy T, Lek M, Samocha KE, Cummings BB, et al; The Exome Aggregation Consortium: The ExAC browser: Displaying reference data information from over 60000 exomes. Nucleic Acids Res 45 (D1): D840-D845, 2017.

21. National Center for Biotechnology Information (US): General Information about dbSNP as a Database Resource. In: SNP FAQ Archive [Internet]. National Center for Biotechnology Information (US), Bethesda, MD, 2005.

22. Cayrefourcq L, Mazard T, Joosse S, Solassol J, Ramos J, Assenat E, Schumacher U, Costes V, Maudelonde T, Pantel K, et al: Establishment and characterization of a cell line from human circulating colon cancer cells. Cancer Res 75: 892-901, 2015.

23. Bliss CI: The calculation of microbial assays. Bacteriol Rev 20: 243-258, 1956

24. Tiriac H, Belleau P, Engle DD, Plenker D, Deschênes A, Somerville TDD, Froeling FEM, Burkhart RA, Denroche RE, Jang GH, et al: Organoid profiling identifies common responders to chemotherapy in pancreatic cancer. Cancer Discov 8: 1112-1129, 2018

25. Douville C, Springer S, Kinde I, Cohen JD, Hruban RH, Lennon AM, Papadopoulos N, Kinzler KW, Vogelstein B and Karchin R: Detection of aneuploidy in patients with cancer through amplification of long interspersed nucleotide elements (LINEs). Proc Natl Acad Sci USA 115: 1871-1876, 2018.

26. Seino T, Kawasaki S, Shimokawa M, Tamagawa H, Toshimitsu K, Fujii M, Ohta Y, Matano M, Nanki K, Kawasaki K, et al: Human Pancreatic Tumor Organoids Reveal Loss of Stem Cell Niche Factor Dependence during Disease Progression. Cell Stem Cell 22: 454-467.e6, 2018.

27. Duffy MJ, Sturgeon C, Lamerz R, Haglund C, Holubec VL, Klapdor R, Nicolini A, Topolcan O and Heinemann V: Tumor markers in pancreatic cancer: A European Group on Tumor Markers (EGTM) status report. Ann Oncol 21: 441-447, 2010.

28. Jones S, Zhang X, Parsons DW, Lin JC, Leary RJ, Angenendt P, Mankoo P, Carter H, Kamiyama H, Jimeno A, et al: Core signaling pathways in human pancreatic cancers revealed by global genomic analyses. Science 321: 1801-1806, 2008.

29. Ellis MJ, Ding L, Shen D, Luo J, Suman VJ, Wallis JW, Van Tine BA, Hoog J, Goiffon RJ, Goldstein TC, et al: Whole-genome analysis informs breast cancer response to aromatase inhibition. Nature 486: 353-360, 2012.

30. Wagner AH, Devarakonda S, Skidmore ZL, Krysiak K, Ramu A, Trani L, Kunisaki J, Masood A, Waqar SN, Spies NC, et al: Recurrent WNT pathway alterations are frequent in relapsed small cell lung cancer. Nat Commun 9: 3787, 2018. 
31. Pietzak EJ, Bagrodia A, Cha EK, Drill EN, Iyer G, Isharwal S, Ostrovnaya I, Baez P, Li Q, Berger MF, et al: Next-generation Sequencing of Nonmuscle Invasive Bladder Cancer Reveals Potential Biomarkers and Rational Therapeutic Targets. Eur Urol 72: 952-959, 2017.

32. Jiang YZ, Ma D, Suo C, Shi J, Xue M, Hu X, Xiao Y, Yu KD, Liu YR, Yu Y, et al: Genomic and Transcriptomic Landscape of Triple-Negative Breast Cancers: Subtypes and Treatment Strategies. Cancer Cell 35: 428-440.e5, 2019.

33. Christen F, Hoyer K, Yoshida K, Hou HA, Waldhueter N Heuser M, Hills RK, Chan W, Hablesreiter R, Blau O, et al: Genomic landscape and clonal evolution of acute myeloid leukemia with $\mathrm{t}(8 ; 21)$ : An international study on 331 patients. Blood 133: 1140-1151, 2019.

34. Penchev VR, Rasheed ZA, Maitra A and Matsui W: Heterogeneity and targeting of pancreatic cancer stem cells. Clin Cancer Res 18 4277-4284, 2012.

35. Tobita K, Kijima H, Dowaki S, Kashiwagi H, Ohtani Y, Oida Y, Yamazaki H, Nakamura M, Ueyama Y, Tanaka M, et al: Epidermal growth factor receptor expression in human pancreatic cancer: Significance for liver metastasis. Int J Mol Med 11: 305-309, 2003

36. Dugan MC, Dergham ST, Kucway R, Singh K, Biernat L, Du W, Vaitkevicius VK, Crissman JD and Sarkar FH: HER-2/neu expression in pancreatic adenocarcinoma: Relation to tumor differentiation and survival. Pancreas 14: 229-236, 1997.

37. Foley K, Kim V, Jaffee E and Zheng L: Current progress in immunotherapy for pancreatic cancer. Cancer Lett 381: 244-251, 2016.

38. Brahmer JR, Tykodi SS, Chow LQM, Hwu WJ, Topalian SL, Hwu P, Drake CG, Camacho LH, Kauh J, Odunsi K, et al: Safety and activity of anti-PD-L1 antibody in patients with advanced cancer. N Engl J Med 366: 2455-2465, 2012.
39. Kongkanuntn R, Bubb VJ, Sansom OJ, Wyllie AH, Harrison DJ and Clarke AR: Dysregulated expression of $\beta$-catenin marks early neoplastic change in Apc mutant mice, but not all lesions arising in Msh2 deficient mice. Oncogene 18: 7219-7225, 1999.

40. Giles RH, van Es JH and Clevers H: Caught up in a Wnt storm: Wnt signaling in cancer. Biochim Biophys Acta 1653: 1-24, 2003

41. Balmanno $\mathrm{K}$ and Cook SJ: Tumour cell survival signalling by the ERK1/2 pathway. Cell Death Differ 16: 368-377, 2009.

42. Hayes TK, Neel NF, Hu C, Gautam P, Chenard M, Long B, Aziz M, Kassner M, Bryant KL, Pierobon M, et al: Long-Term ERK Inhibition in KRAS-Mutant Pancreatic Cancer Is Associated with MYC Degradation and Senescence-like Growth Suppression. Cancer Cell 29: 75-89, 2016.

43. Pollock PM,Harper UL, Hansen KS, Yudt LM, Stark M, Robbins CM, Moses TY, Hostetter G, Wagner U, Kakareka J, et al: High frequency of BRAF mutations in nevi. Nat Genet 33: 19-20, 2003.

44. Davies H, Bignell GR, Cox C, Stephens P, Edkins S, Clegg S, Teague J, Woffendin $\mathrm{H}$, Garnett MJ, Bottomley W, et al: Mutations of the BRAF gene in human cancer. Nature 417: 949-954, 2002.

45. Jeong WJ, Yoon J, Park JC, Lee SH, Lee SH, Kaduwal S, Kim H, Yoon JB and Choi KY: Ras stabilization through aberrant activation of $\mathrm{Wnt} / \beta$-catenin signaling promotes intestinal tumorigenesis. Sci Signal 5: ra30, 2012.

46. Edge SB, Byrd DR, Compton CC, Fritz AG, Greene FL and Trotti A (eds): AJCC Cancer Staging Manual. 7th edition. American Joint Committee on Cancer, Chicago, IL, 2010.

This work is licensed under a Creative Commons Attribution-NonCommercial-NoDerivatives 4.0 International (CC BY-NC-ND 4.0) License. 